\title{
Satisfaction among patients attending Oncology clinic in a tertiary hospital in South West, Nigeria.
}

\author{
Kuyinu Y.A. ${ }^{1}$, Onyemenam J.H. ${ }^{2},{ }^{*}$ Goodman O.O. ${ }^{1}$, Odugbemi B.A.
}

\begin{abstract}
Objective: This study determined patients' satisfaction with health care received at the oncology clinic in a tertiary hospital in Lagos, South West of Nigeria.

Methods: A descriptive cross-sectional study was carried out among patients attending the oncology clinic in Lagos State University Teaching Hospital, Ikeja, Lagos. A total of 143 patients were recruited using a systematic random sampling and interviewer administered questionnaire was used to collect data. Analysis was done using Statistical Package for Social Sciences (SPSS version 20). Test of significance was performed using a $95 \%$ confidence interval and the level of significant set at $\mathrm{p}=0.05$.

Results: More than half $123(86.1 \%)$ reported that they got the kind of service they wanted, $125(87.5 \%)$ reported almost all their needs had been met. Majority (92.3\%) of the respondents were satisfied with the level of care received while $2.8 \%$ were indifferent and $7(5 \%)$ were dissatisfied. The level of satisfaction was statistically significantly associated with age, marital status, level of education and average monthly income $(\mathrm{p}<0.05)$.
\end{abstract}

Conclusion: Majority of patients were satisfied with the health care services at the oncology clinic. Regular satisfaction survey is recommended.

Key words: Patient satisfaction, oncology, tertiary hospital

\author{
*Corresponding author \\ Goodman O. \\ http://orcid.org/0000-0003-0930-5989 \\ Email: yinkagoodman@yahoo.com \\ ${ }^{1}$ Lagos state University College of Medicine, Ikeja, Lagos \\ ${ }^{2}$ Lagos state University Teaching Hospital, Ikeja, Lagos
}




\title{
Satisfaction des patients fréquentant une clinique d'oncologie dans un hôpital tertiaire du sud-ouest du Nigéria.
}

\author{
Kuyinu Y.A. ${ }^{1}$, Onyemenam J.H. ${ }^{2}$, ${ }^{\text {Goodman O.O. }}{ }^{1}$, Odugbemi B.A.
}

\begin{abstract}
Abstrait
Objectif: Cette étude a permis de déterminer la satisfaction des patients à l'égard des soins de santé reçus à la clinique d'oncologie située dans un hôpital tertiaire de Lagos, dans le sud-ouest du Nigéria.
\end{abstract}

Méthodes: Une étude transversale descriptive a été réalisée auprès de patients fréquentant la clinique d'oncologie de l'hôpital universitaire de l'État de Lagos, à Ikeja (Lagos). Au total, 143 patients ont été recrutés à l'aide d'un échantillonnage aléatoire systématique et d'un questionnaire à l'aide d'un intervieweur a été utilisé pour collecter des données. L'analyse a été réalisée à l'aide du progiciel statistique pour les sciences sociales (SPSS version 20). Le test de significativité a été réalisé en utilisant un intervalle de confiance de $95 \%$ et le niveau de significativité défini à $\mathrm{p}=0,05$.

Résultats: Plus de la moitié des répondants $(86,1 \%)$ ont déclaré avoir obtenu le type de service qu'ils souhaitaient et $125(87,5 \%)$ ont indiqué que presque tous leurs besoins avaient été satisfaits. La majorité $(92,3 \%)$ des répondants étaient satisfaits du niveau de soins reçus, $2,8 \%$ étaient indifférents et $7(5 \%)$ insatisfaits. Le niveau de satisfaction était statistiquement associé de manière significative à l'âge, à l'état matrimonial, au niveau d'éducation et au revenu mensuel moyen $(\mathrm{p}<0,05)$.

Conclusion: La majorité des patients étaient satisfaits des services de santé fournis par la clinique d'oncologie. Une enquête de satisfaction régulière est recommandée.

Mots-clés: Satisfaction des patients, oncologie, hôpital tertiaire

\author{
*Auteur principal \\ Goodman O. \\ http://orcid.org/0000-0003-0930-5989 \\ Email:yinkagoodman@yahoo.com \\ ${ }^{1}$ Lagos state University College of Medicine, Ikeja, Lagos \\ ${ }^{2}$ Lagos state University Teaching Hospital, Ikeja, Lagos
}




\section{INTRODUCTION}

Cancer impacts human life in diverse ways including patient oriented outcomes such as quality of life. With this realization, attention to outcomes such as patient satisfaction is becoming very important (1). Thus, patients' perspective in the evaluation of treatment efficacy and overall care is being systematically pursued (2). It may appear that health care which improves health only in some limited technical sense but the quality and length of life may not be viewed as important by patients (3). There is therefore a growing interest in evaluation of the delivery of care from the perspective of patients (4).

"Patient satisfaction" is not a unitary concept but rather a distillation of perceptions and values (5). Perceptions are patients' beliefs about occurrences, while satisfaction is a person's feeling of pleasure or disappointment resulting from comparing services/ products, perceived performance or outcome in relation to his or her expectations (5). Values are the weights patients apply to those occurrences. They reflect the degree to which patients consider specific occurrences to be desirable, expected, or necessary (5). If performance falls short of expectation, the patient is dissatisfied and if performance matches expectation, the patient is satisfied. In addition, if performance exceeds expectation then the patient is highly satisfied or elated (6). The health system especially in developing countries seeks to achieve a balance in service that offers clinically effective care that is evidence based and also what patients judge as acceptable and beneficial $(1,2)$. Thus patient satisfaction, has now been recognized as one of the key indicators of health care quality and is being used by health care institutions for monitoring health care improvement programs, gaining accreditation, and marketing strategies in countries including Africa $(2,7,8)$.

Patient-centered care can be defined as 'care that is respectful of and responsive to individual patient preferences, need, values, ensuring that patient values guide all clinical decisions (9). Patients' reported measures of health care quality aim to include the patients' perspective across a range of quality concerns in the assessment process (2). Well- developed measures, particularly, those that have involved patients in development, provide an important resource for assessing and communicating the quality of healthcare (2). Evaluation of the best possible care for cancer patients should include aspects that are linked to the patients' quality of life, personal aspirations, values and quality and their relations and needs rather than medical aspect as a single entity (10).

Cancer is a global disease, and is an increasingly important public health problem in health care systems in developing countries. It is a leading cause of morbidity and mortality worldwide and death from cancers are projected to continue rising with an estimated 13.3 million deaths in 2030 (7). Much of the burden of cancer incidence, morbidity and mortality will occur in the developing countries such as Nigeria $(7,8)$. Cancer patients usually encounter physical and emotional problems that are substantially different from patients without a life threatening disease. They usually experience long- term uncertainty and concerns about the nature, course and prognosis of their illness (1). They inevitably face continued dependency on health care providers, for lengthy treatment, medical followup or rehabilitation (2). Thus, the patient diagnosed as having cancer has increased susceptibility to stress resulting from a positive diagnosis of cancer, its treatment, and possible prognosis $(1,2)$. These patients' stress can be amplified by long waiting room times, lack of information, poor communication between clinic staff and patients, and the absence of psychosocial care $(1,2)$. It is important to have an insight to the patient's view on health care and on their specific wishes, needs and preferences, in order to improve health care delivery to cancer patients (9). This study therefore aimed to determine patients' satisfaction with health care received at the oncology clinic in Lagos State University Teaching Hospital, Ikeja, Lagos.

\section{MATERIALS AND METHODS}

The descriptive cross-sectional study took place at the oncology clinic in Lagos State University Teaching Hospital (LASUTH), located in Ikeja. LASUTH is a tertiary hospital owned by the Lagos State Government, though the State hosts other tertiary health facilities owned by the Federal government and individuals. The Oncology clinic at LASUTH receives patients referred from private hospitals and other primary and secondary facilities (11). Clinic days holds twice every week, excluding public holidays and has an average of 270 patients attending monthly. The clinic offers mainly consultations and treatment to patients, while investigations and other services are provided outside of the clinic.

Sample size was calculated using the formula for single proportions $(12,13)$ at a precision of $5 \%$ and proportion of $89 \%$ from a 
study on patient satisfaction in oncology clinic (LIS) (14). After finite population correction for proportions (sample size for small proportions) in populations $<10,000$, the sample size required was 96. However, 143 Patients were recruited into the study using a systematic random sampling method with a sampling fraction of 2 (obtained using the average number of attendees by the total sample size). The study was conducted among patients (new and returning) receiving treatment in the oncology clinic for any type of cancer (having had a pathological diagnosis of any form of cancer). Patient less than 18 years old and those with known or suspected psychotic disease or mental retardation were excluded from the study. Number of respondents to be interviewed in each clinic day was obtained by dividing the number of clinic days in the data collection period (1 month) by the sample size i.e., $143 / 8=17.8$ (approximately 18 respondents). Study instrument was a structured questionnaire which was pretested on patients attending the oncology clinic at another tertiary hospital in Lagos. Data was collected by three trained research assistants by interviews and the interviews took place after patients' clinic consultation. Ethical approval was obtained from Research and Ethics Committee of LASUTH and a written consent was obtained from study participants. Study duration was one year.

Data analysis was done using Statistical Package for Social Sciences (SPSS version 20) and findings were presented in frequency tables and cross tabulations. The Chi-square table was used for comparison of categorical variables. Test of significance was performed using a 95\% confidence interval and the level of significant set at $p=0.05$. Satisfaction was categorized as satisfied or dissatisfied (15).

\section{RESULTS}

A total of one hundred and forty three patients (143) were recruited into the study and females made up $126(88.1 \%)$ of the respondents. The mean age of the respondents was $49.0( \pm 13)$ years and majority was between the ages $60-69$ years (28.7\%), and $40-49$ years (24.5\%). Majority 95 (66.4\%) were married while 12 $(8.4 \%)$ were single. A greater proportion of the respondents $50(35 \%)$ had tertiary level of education and $14(9.8 \%)$ of respondents had no formal education.

More than half $83(58.0 \%)$ of the respondents were employed. Majority 63 (44.1\%) had a monthly income between N26, $000-\mathrm{N} 50,000$ while $25(17.5 \%)$ had an income of above Fifty Thousand Naira.

A little above half, (52.4\%) of the respondents spent greater than 1 hour on the road from their homes, to the clinic. Fifty eight $(40.6 \%)$ had been attending the clinic for 6months-1year.

One hundred and twenty seven of the respondents $(88.8 \%)$ indicated that the hospital was adequately surrounded by flowers, $139(97.2 \%)$ reported the hospital environment was not littered with papers, $4(2.1 \%)$ indicated that refuse was not well disposed. Majority 132 (92.3\%) said the hospital did not emit offensive odour and $110(83.9 \%)$ said the hospital environment was well decorated. A greater percentage $139(97.2 \%)$ agreed that files were properly arranged in the consulting rooms. Only four $(2.8 \%)$ said used syringes were not properly disposed. Majority 139 (97.2\%) agreed that the internal and external building was well painted. A greater percentage; $73.4 \%, 89.5 \%, 72.0 \%$ and $95.8 \%$ indicated the clinic had air conditioning, fan and television; and comfortable chairs respectively.

The majority of the respondents did not experience any disrespectful act from any of the health personnel, $136(95.1 \%)$ and 127 (88.8\%) have not been abused nor had their request ignored. More than half $107(54.8 \%)$ spent greater than 1 hour waiting to see the doctor, $42(29.4 \%)$ and $38(26.6 \%)$ felt waiting between 45 to 1 hour and between 15 to 29 minutes respectively would be their ideal time to wait before being seen by the doctor. A lesser percentage of respondents 12 (8.4 percent) said they have left the hospital without seeing a doctor, and half of these $6(50.0 \%)$ said they waited greater than 1 hour before leaving. However, $6(4.2 \%)$ of the respondents felt the time the doctor spent attending to their complaint was too short.

Majority of the respondents $112(78.3 \%)$ rated their level of satisfaction with the overall quality of service as good. More than half 123 (86.1\%) agreed they got the kind of service they wanted, while $125(87.5 \%)$ said almost all their needs had been met. All the respondents reported that the services rendered helped them deal more effectively with their problems. Majority 137 $(95.8 \%)$ of the respondents felt the doctor spent enough time with them during their visit and 130 $(91 \%)$ said they were satisfied with the way the doctor treated their problem.

Majority of respondents 129 $(90.2 \%)$ were satisfied with the range of treatment offered them. Similarly, majority 135 $(94.4 \%)$ agreed they would definitely come back 
to the clinic to seek help if the need arose, and 135 (94.4\%) said they would definitely recommend the services of the oncology clinic to any friend in need of help. Majority 132 (92.3 percent) of the respondents were satisfied with the level of care they received while $(7.7 \%)$ were not. There was no statistically significant association between level of satisfaction and any of the factors investigated.

\section{DISCUSSION}

One hundred and forty-three oncology patients receiving treatment at the time of the study in the Lagos State University Teaching Hospital's oncology clinic were enrolled for this study. There were four times more females than males and the majority was married suggesting they could have the benefit of spousal support. The population was well educated with the most of them having a minimum of secondary education.

Geographical accessibility was determined by commuting time to the clinic. Although the majority reported being able to get to the clinic easily, more than half traveled for over an hour to get to the clinic. Waiting time to see the doctor, was estimated to be greater than 1 hour by more than half $(54.8 \%)$ of the respondents. This delay is too long and inappropriate for chronically ill individuals on a scheduled appointment. This however could be due to the high patient load relative to health workers and also the availability of only few of such clinics in an urban metropolis. Waiting time as a single parameter appears not to determine patients' satisfaction with service received. This was also reported in a study done using inpatients with oesophageal and gastric cancers (16). Other determinants of overall satisfaction may include hospital comfort, cleanliness and encounters with doctors and nurses (16). Perception of satisfaction works best where patients understand what to expect from the system, otherwise, patients can adjudge substandard services received as satisfying.

Educating patient on their condition is a powerful tool and recognized as good practice especially with chronic diseases. In this study, more than $80 \%$ of the patients were satisfied with information they had received. Impacts of physician's behaviors including communication on patient's satisfaction have been considered by studies $(2,17)$. Patients were generally satisfied with their physicians regardless of treatment intensity; they were most satisfied with the physician's honesty, thoroughness, and communication (17). Respondents also expressed high satisfaction with the information given them by health workers. This was similar to another study on cancer patients satisfaction with care, where few patients were dissatisfied with the provision of information concerning their disease and treatment (18) another study done in a neurooncology clinic in Europe showed only one patient was dissatisfied with the delivery of information (19). In spite of the favorable rating, the health care providers should make extra effort to ensure those with negative responses understand health information through better inter-personal communication. From a study carried out in a large oncology out-patient clinic, it was deduced that patients who judged themselves as well informed were significantly more satisfied with consultation than those who lacked sufficient information (20).

In this study majority of the respondents were satisfied with the treatment range offered them ( $90.2 \%$ being satisfied), this was in contrast with the result of the study carried out using breast cancer patients in Britain where $78 \%$ of the respondent had perceived no choice in their treatment range, as they claimed they 'follow the doctor's advice' (21).

The willingness to recommend an oncology facility to friends or relatives in need of the services has been interpreted to be a key indicator of patients' satisfaction. In this study, there was a high level of patient's willingness to recommend the facility to others if there was a need (Table 3). In another study carried out in Germany on patient satisfaction and quality of life in cancer outpatients, it was found that Patient-provider relationship, facility setting and information on diagnosis and treatment options were major determinants of a patient's willingness to recommend a facility to a friend or relative if needed (22). This study however did not identify determinants of patients' willingness to recommend facility.

Overall level of satisfaction with service was rated as satisfactory by $92.3 \%$ of respondents in this study (Table 4). This finding is better than findings from a study done in a tertiary hospital in South east Nigeria (23). Similarly, another study carried out in a teaching hospital in Northern Nigeria had $83 \%$ of their respondents satisfied with the health services rendered (24). The high level of satisfaction in this study could be due to the high opinion on physical environment and staff attitudes expressed.

Relating the age of the respondents with the level of overall satisfaction showed that there 
was no association between age and the level of satisfaction with health care services. This is contrary to the findings of several oncology surveys where it was reported that older people were more satisfied with health care services than younger ones (25-28). Cancer treatment, though subsidized, is usually paid for out of pocket. This study did not find a difference in level of satisfaction between different socioeconomic groups.

With reference to respondents' recommendations on ways to improve quality of services, $59.4 \%$ of respondents suggested that the staff strength should be increased, $55.9 \%$ of total respondents suggested that hospital waiting time be reduced while $20.9 \%$ of respondents felt that more equipment should be provided. Only $13.9 \%$ of the total respondents suggested that strike actions should be avoided. This was so, because oncology patients have access to their doctors even after the close of work (via telephones), and scheduled chemotherapy for patients were administered even when there was an on-going strike action. Majority of the respondents $(94.4 \%)$ were of the opinion that treatment cost be subsidized/ reduced.

\section{CONCLUSION}

The study showed that there is a high level of overall satisfaction with the health care services received at the oncology clinic of the Lagos State University Teaching hospital, Ikeja, Lagos state. There is need to carry out a periodic assessment of patients' satisfaction with the care received at health facilities in order to meet patients' expectation and also a need to carry out a more objective assessment of the quality of care provided to patients.

Acknowledgement: Authors acknowledge the assistance of nurses and doctors at the Oncology Clinic of LASUTH for helping to facilitate this study.

\section{Conflict of interest: None.}

\section{REFERENCES}

1. Bredart A, Razavi D, Robertson C, et al. A Comprehensive assessment of satisfaction with care: Preliminary psychometric analysis in French, polish, Swedish and Italian oncology patient. Patient Education Counseling 2001; 43(3): 243-253.

2. Lis CG, Rodeghier M and Gupta D. Distribution and determinants of patient satisfaction in oncology: A review of the literature. Patient Prefer Adherence 2009; 3(41): 287-304.
3. Jenkinson C, Coulter A, Bruster S, Richards N, Chandola T. Patients' experiences and satisfaction with health care. Results of a questionnaire study of specific aspects of care. Quality Safe Health Care 2003; 11(4): 335-339.

4. Howard JE. Customer service. The key to remaining competitive in managed care. Managed care quarterly. 2000; 8(2): 22- 29.

5. Youssef H. Determining patient satisfaction with medical care. International Journal on quality health care 2007; 29(6):2-57.

6. Alaiban KM, Al-Omar B, Narine L, et al. A survey assessing patient satisfaction at public and private healthcare facilities in Riyadh, Saudi Arabia. Ann Saudi Med. 2003; 23(6):417-419.

7. GLOBOCAN: Cancer incidence and Mortality Worldwide. http://globocan.iarc.fr. (2008, accessed on 02 December 2013).

8. Popoola.AO, Omodele FO, Oludara MA, et al. Prevalence and Pattern of Cancers among Adults Attending a Tertiary Health Institution in Lagos, Nigeria. IOSR Journal of Dental and Medical Sciences 2013; 6(3): 68-73.

9. Patlak M, Balogh E, and Nass S. Rapporteurs; Institute of Medicine Patient Centered Treatment Planning- Improving the quality of onclogy care: Workshop Summary 2011:4.

10. Wessels H, De Graeff A, Wynia K, et al. Medical oncology patients' preferences with regard to health care: development of a patient-driven questionnaire. Annals of Oncology 2009; 20(10): 1708

11. Lagos State Government. Handbook on Lagos State University Teaching Hospital (LASUTH) 2009: 1- 7 .

12. Polonia GFK. Analysis of sample size in consumer surveys Poland. Nov 2013: 6- 7.

13. Cochran WG. Sampling Techniques, 2nd Ed. New York: John Wiley and Sons, Inc. 1963.

14. Gupta D, Rodeghier M and Lis CG. Patient satisfaction with service quality in an oncology setting: implications for prognosis in non-small cell lung cancer. International Journal for Quality in Health Care 2013; 25( 6): 696-703.

15. Hojat M, Louis DZ, Maxwell K, et al. A brief instrument to measure patients' overall satisfaction with primary care physicians. Fam Med 2011;43(6):412-417.

16. Kavadas V, Barham CP, Finch- Jones MD, et al. Assessment of satisfaction with care after inpatient treatment for oesophageal and gastric cancer. Br J Surg. 2004; 91(6): 719- 723.

17. Landen CN Jr, Younger NO, Collins Sharp BA, et al. Cancer patients' satisfaction with physicians: Princess Margaret Hospital Satisfaction with Doctor Questionnaire results. Am J Obstet Gynecol. 2003; 188(5):1177-1179.

18. Wiggers JH, Donovan KO, Redman S, et al. Cancer patient satisfaction with care. Cancer. 1990; 66(3): 610- 616.

19. McNamara S and Brown J. An audit of patient satisfaction with a Neuro-Oncology clinic. Eur J 
Oncol Nurs. 2003; 7(3):200- 203.

20. Fossa SD, Hjermstad MJ, Mork IH, et al. Does the service at a large oncology out-patient clinic satisfy the patients' perceived need? Int J Health Care Qual Assur. 1996; 9(4): 24-29.

21. Jansen SJ, Otten W, Van de Velde CJ, et al. The impact of the perception of treatment choice on satisfaction with treatment, experienced chemotherapy burden and current quality of life. Br J Cancer. 2004; 91(2): 56- 61

22. Kleeberg UR, Tews JT, Ruprecht T. Patient satisfaction and quality of life in cancer outpatients: results of the PASQOC study. Support Care Cancer, 2005; 13(5): 303-310

23. Daniel OJ. Patient Satisfaction with health services at the out-patient department of a Tertiary hospital in Nigeria. Nigerian Journal of Clinical Medicine 2013; 5(1):2.

24. Lliyasu Z, Abubakar IS, Abubakar S, et al.
Patients' satisfaction with services obtained from Aminu Kano Teaching Hospital, Kano, Northern Nigeria. Nigerian Journal of Clinical Medicine 2010; $13(4)$ : 371-378.

25. Zastoway TR, Roghmann KJ, Haugst C, et al Satisfaction with medical care: replication and theoretical re-evaluation. Scandinavian Journal of Caring Sciences 2002; 16(3) :329-33.

26. Davidson R and Mills ME. Cancer patients' satisfaction with communication, information and quality of care in a Uk region. Eur J Cancer Care (Engl) 2005; 14(1): 83-90.

27. Bredart A, Bouleuc C, Dolbeault S. Doctorpatient communication and satisfaction with care in oncology. Curr Opin Oncol 2005; 17(4): 351354.

28. Sandoval GA, Brown AD, Sullivan T, et al. Factors that influence cancer patients overall perception of the quality of care. Int J Qual Health Care 2006; 18(4): 266- 274. 